\title{
APRENDIZAGEM SIGNIFICATIVA COM ENFOQUE NO DESENVOLVIMENTO AUTÔNOMO DO ESTUDANTE
}

\section{SIGNIFICANT LEARNING WITH A FOCUS ON STUDENT AUTONOMOUS DEVELOPMENT}

\author{
Anderson Luiz Ellwanger ${ }^{1}$ \\ Marcos Alexandre Alves ${ }^{2}$ \\ Solange Binotto Fagan ${ }^{3}$
}

RESUMO:Neste trabalho apresentamos uma análise de produções científicas sobre ensino de Ciências, com foco na Aprendizagem Significativa, e com especial destaque no desenvolvimento autonomia, publicados em periódicos da área de Ensino de Ciências, no período de 2010 a 2014. Fizeram parte desta análise seis periódicos nacionais $\mathrm{A} 1 \mathrm{e}$ o banco de teses da CAPES. Para o desenvolvimento desta investigação tomamos a análise textual como metodologia geral para a coleta e análise de dados. Para a sistematização das informações foram destacadas três vertentes: a) A melhora na motivação dos estudantes frente ao conteúdo curricular. b) indícios de aprendizagem significativa com vistas a autonomia do estudante e c) formas de investigação. As análises realizadas permitiram a delimitação de um corpus de pesquisa, o qual constitui o ponto de partida para uma reflexão mais ampla e detalhada sobre o campo de investigação.

PALAVRAS-CHAVE: Ensino de Ciências; Análise Textual; Aprendizagem Significativa; Autonomia

ABSTRACT:We present an analysis of scientific productions on science teaching, focusing on Meaningful Learning, and with special emphasis on the development of autonomy, published in journals of science education area during the period

\footnotetext{
${ }^{1}$ Doutorando pelo Programa de Pós-Graduação em Ensino de Ciências e Matemática. Centro Universitário Franciscano - UNIFRA. Professor Assistente do Curso de Física - Centro Universitário Franciscano - UNIFRA. Santa Maria, Rio Grande do Sul, Brasil. pfandd@gmail.com

${ }^{2}$ Doutor em Filosofia da Educação - Professor Adjunto do Curso de Filosofia e do Programa de Pós-Graduação em Ensino de Ciências e Matemática. Centro Universitário Franciscano - UNIFRA. Santa Maria, Rio Grande do Sul, Brasil.maralexalves@gmail.com.

${ }^{3}$ Doutora em Física - Professora Titular do Curso de Física Médica e do Programa de Pós-Graduação em Ensino de Ciências e Matemática. Pró-reitora de Pós-graduação, Pesquisa e Extensão. Centro Universitário Franciscano - UNIFRA. Santa Maria, Rio Grande do Sul, Brasil. solange.fagan@gmail.com
} 
from 2010 to 2014 . They were part of this analysis six national newspapers and the A1 bank of CAPES theses. To develop this research we textual analysis as a general methodology for data collection and analysis. To the systematization of information were highlighted three aspects: a) The improvement in students' motivation across the curriculum content. b) significant learning of evidence with a view to autonomy of the student c) forms of research. The analyzes allowed the delimitation of a research corpus, which is the starting point for a more comprehensive and detailed reflection on the field.

KEYWORDS: Science Teaching; Textual Analysis; Independent learning.

\section{Introdução}

O ensino de Ciência, e seus problemas, vêm sendo discutido e pesquisado por professores e especialistas há muito tempo. Cada vez mais, torna-se unânime entre os professores de ciências uma crescente sensação de desassossego e frustração, pois se percebe que os alunos estão desmotivados e passivos, por isso aprendem cada vez menos e têm menos interesse pelo que aprendem. Essa crise da educação científica, que se manifesta não só nas salas de aula, mas também nos resultados da pesquisa em didática das ciências mostram que muitos professores de ciências percebem que a maioria dos alunos não aprende a ciência que Ihes é ensinada. Identifica-se nos alunos dificuldades conceituais, problemas no uso de estratégias de raciocínio e resolução de problemas próprios do trabalho científico.

Além disso, constatam-se dificuldades no domínio daquilo que podemos chamar de conteúdos procedimentais do currículo de ciências - aprender a fazer com seus conhecimentos científicos. Muitas vezes, os alunos não conseguem adquirir as habilidades necessárias, seja para elaborar um gráfico a partir de alguns dados ou para observar corretamente através de um microscópio, mas outras vezes o problema é que eles sabem fazer as coisas, mas não entendem o que estão fazendo e, portanto, não conseguem explicá-las nem as aplicar em novas situações.

Mesmo quando os professores acreditam que seus alunos aprenderam algo, e de fato comprovam esse aprendizado por meio de uma avaliação, o que foi aprendido se dilui ou se torna difuso rapidamente quando se trata de aplicar esse conhecimento a um problema ou situação nova, ou assim que se pede ao aluno uma explicação sobre o que ele está fazendo. Essas dificuldades 
tornam-se evidentes na resolução de problemas, pois os alunos tendem a enfrentá-los de um modo repetitivo, como simples exercícios rotineiros, em vez de encará-los como tarefas abertas que exigem reflexão e tomada de decisões.

Essas dificuldades de aprendizagem e suas possíveis soluções são consequência das próprias práticas escolares de resolução de problemas, que tendem a centrar-se em tarefas rotineiras ou delimitadas, com escasso significado científico do que em verdadeiros problemas com conteúdo científico. Essa perda de sentido do conhecimento científico não só limita sua utilidade ou aplicabilidade, por parte dos alunos, mas também seu interesse ou relevância. Como consequência do ensino recebido, os alunos adotam atitudes inadequadas ou mesmo incompatíveis com os próprios fins da ciência, que se traduzem, sobretudo, em uma falta de motivação ou interesse pela aprendizagem desta disciplina, além de uma escassa valorização de seus saberes.

Além dessa falta de interesse, os alunos tendem a assumir atitudes inadequadas com respeito ao trabalho científico, ou seja, posições passivas: esperam respostas prontas em vez de dá-las, e muito menos são capazes de fazer eles mesmos as perguntas; concebem os experimentos como demonstrações e não como pesquisas; assumem que o trabalho intelectual é uma atividade individual e não de cooperação e busca conjunta; consideram a ciência como um conhecimento neutro, desligado de suas repercussões sociais; assumem a superioridade do conhecimento científico com respeito a outras formas de saber. Enfim, essa imagem da ciência, que na verdade não corresponde ao que os cientistas realmente fazem, é mantida e reforçada implicitamente por meio da atividade cotidiana na sala de aula.

A defasagem entre as atitudes supostamente buscadas e as obtidas nos alunos, com especial ênfase no eterno problema da (des)motivação desses pela aprendizagem da ciência. Ora, a educação científica também deveria promover e modificar certas atitudes nos alunos, algo que não consegue, em parte porque os professores de ciências não costumam considerar que a educação em atitudes faça parte de seus objetivos e conteúdos essenciais, apesar das atitudes dos alunos nas salas de aula serem um dos elementos mais incômodos.

A deterioração do clima educacional nas salas de aula e nas escolas, e o desajuste crescente entre as metas dos professores e as dos alunos são alguns dos sintomas inquietantes desta crise da educação científica. Esse fenômeno se traduz em uma suposta queda dos níveis de aprendizagem dos alunos, em uma considerável desorientação entre os professores diante da multiplicação das demandas educacionais que precisam enfrentar e uma defasagem crescente entre as demandas formativas dos alunos e a oferta educacional. 
As dificuldades que os professores de ciências enfrentam nas salas de aula quase nunca são consequência da aplicação de novas propostas curriculares, senão que, na maior parte dos casos, ocorrem devido à tentativa de manter um tipo de educação científica que em seus conteúdos, atividades de aprendizagem, critérios de avaliação e metas está muito próxima ao tradicionalismo.

O problema é que o currículo de ciências praticamente não mudou, enquanto a sociedade à qual está sendo dirigido esse ensino e as demandas formativas dos alunos mudaram. O desajuste entre a ciência que é ensinada e os próprios alunos é cada vez maior, refletindo uma autêntica crise na cultura educacional, que requer adotar não apenas novos métodos, mas novas metas, nova cultura educacional que podemos vincular ao chamado construtivismo ${ }^{4}$. A nova cultura da aprendizagem que se abre neste século é dificilmente compativel com formatos escolares e metas educacionais que praticamente não mudaram desde que as instituições escolares foram constituídas.

Como atenuar este panorama? Como aumentar a participação efetiva dos estudantes? Como mantê-los comprometidos e motivados? Esses e outros questionamentos parecem ser explicados pela proposta da teoria da Aprendizagem Significativa (AS), com foco na autonomia do estudante, e fundamentada na epistemologia construtivista. Segundo essa orientação, almeja-se uma maior participação do estudante no processo de construção/ reconstrução do conhecimento, ou seja, busca-se a autonomia com o objetivo de manter os estudantes em constante processo de assimilação e produção do conhecimento.

A Aprendizagem Significativa (AS) com vistas à autonomia incentiva o uso de múltiplas metodologias de ensino (situações problema, experimentação, ensino pela pesquisa, produção de conhecimento, entre outras) que podem ser mediadas pelas tecnologias de informação e comunicação, muito familiares aos estudantes, de forma presencial ou virtual. Nesta perspectiva o estudante deixa de ser apenas expectador e pode ser mais atuante na sua instrução (MOTA; SCOTT, 2014).

Com isto em mente, objetiva-se, por meio dessa pesquisa, investigar e apresentar o atual balanço de produção sobre o ensino de ciência, mapear as produções acadêmicas dos últimos cinco anos que indicam: a) a melhora

\footnotetext{
${ }^{4} \mathrm{O}$ construtivismo sustenta a ideia de o indivíduo, tanto nos aspectos cognitivos quanto sociais do comportamento como nos afetivos, não é um mero produto do ambiente nem um simples resultado de suas disposições internas, mas, sim, uma construção própria que vai se produzindo, dia a dia, como resultado da interação entre esses dois fatores. Em consequência, segundo a posição construtivista, o conhecimento não é uma cópia da realidade, mas, sim, uma construção do ser humano (CARRETERO, 1997).
}

Rev. Fac. Educ. (Univ. do Estado de Mato Grosso), Vol. 28, Ano 15, № 2 p. 75-97, jul./dez. 2017 
na motivação dos estudantes frente ao conteúdo curricular; b) indícios de aprendizagem significativa com vistas à autonomia do estudante e; c) diferentes formas de investigação. Nesse sentido, passamos agora a explicitar a revisão de literatura, feita nos periódicos científicos, a respeito do tema em questão.

\section{Revisão de literatura em periódicos nacionais}

Para a revisão de literatura foram pesquisados periódicos nacionais, compreendendo os anos 2010 até 2014 . A busca pelos artigos que tratavam da referida questão, ocorreu, inicialmente, por meio da análise do título, em seguida a partir da leitura do resumo e se necessário foi feita a leitura do artigo por inteiro. Na tabela 01, foram elencadas as revistas pesquisadas, bem como, os títulos e os autores destes artigos que envolvem a temática.

Tabela 01: Relação das revistas pesquisadas e os artigos disponíveis em cada uma delas que envolvem o tema

\begin{tabular}{|c|c|}
\hline Revista & Artigos \\
\hline $\begin{array}{l}\text { Investigações em Ensino de Ciências } \\
\text { http://www.if.ufrgs.br/ienci/?go=home }\end{array}$ & $\begin{array}{l}\text { FABRI e SILVEIRA (2013); } \\
\text { HILGER e GRIEBELER (2013); } \\
\text { LANGHI e NARDI (2011); } \\
\text { CARLETTO e PINHEIRO (2010); } \\
\text { GATTI, NARDI ESILVA (2010); } \\
\text { TEIXEIRA et al. (2010); } \\
\text { TOTI e PIERSON (2010). } \\
\text { MASSONI (2014); }\end{array}$ \\
\hline $\begin{array}{l}\text { Caderno Brasileiro de Ensino de } \\
\text { Ciências } \\
\text { https://periodicos.ufsc.br/index.php/ } \\
\text { fisica/index }\end{array}$ & $\begin{array}{l}\text { BELLUCCO e CARVALHO (2014); ARAUJO } \\
\text { e MAZUR (2013); } \\
\text { CUSTÓDIO, PIETROCOLA e SOUZA } \\
\text { CRUZ(2013); } \\
\text { COELHO, TIMM E SANTOS (2010). }\end{array}$ \\
\hline $\begin{array}{c}\text { Revista Brasileira de Ensino de Física } \\
\text { http://www.sbfisica.org.br/rbef/ } \\
\text { edicoes.shtml }\end{array}$ & $\begin{array}{l}\text { CICUTO, MENDES e CORREIA (2013); } \\
\text { CAMPOS et al. (2012). }\end{array}$ \\
\hline $\begin{array}{l}\text { Experiências em Ensino de Ciências } \\
\text { http://if.ufmt.br/eenci/index.php }\end{array}$ & $\begin{array}{l}\text { TAUCEDA, NUNES e DEL PINO (2011); } \\
\text { PEREIRA, SOARES e ANDRADE (2011); } \\
\text { OLIVEIRA et al. (2010); } \\
\text { DARROZ e SANTOS (2012). }\end{array}$ \\
\hline
\end{tabular}




\begin{tabular}{|c|c|}
\hline $\begin{array}{c}\text { Ensaio: pesquisa em educação em } \\
\text { ciências } \\
\text { http://www.portal.fae.ufmg.br/seer/ } \\
\text { index.php/ensaio }\end{array}$ & Nada consta \\
\hline $\begin{array}{c}\text { Revista Brasileira de Pesquisa em } \\
\text { Educação em Ciências } \\
\text { http://revistas.if.usp.br/rbpec/index }\end{array}$ & Nada consta \\
\hline
\end{tabular}

Fonte: Elaborada pelos autores

No gráfico 01, pode-se observar a distribuição dos artigos nos seus respectivos anos de publicação. Além disto, percebe-se que o número de estudos na área permanece, em média, constante, mostrando que o interesse pelo tema pouco se modifica.

Para a pesquisa, utilizou-se do portal de periódicos da Coordenação de Aperfeiçoamento de Pessoal de Nível Superior (CAPES) em que foram usadas as palavras chaves aprendizagem independente, aprendizagem autônoma e aprendizagem significativa com autonomia. A busca foi refinada para a área de Ensino de Ciências. A partir desta estratégia, constatou-se que nenhuma das buscas apresentou resultados.

Gráfico 01 - Número de artigos publicados e seus respectivos anos de publicação.

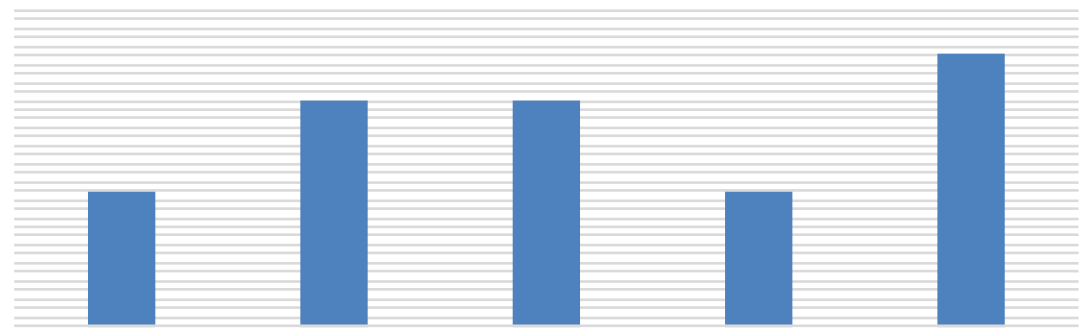

Fonte: Elaborado pelos autores.

Além das pesquisas feitas, diretamente, nas páginas das revistas e no portal de periódicos da CAPES, foi usada a ferramenta de busca Google acadêmico que nos permitiu delimitar a busca nos anos de 2010 até 2014. Neste portal, foram usadas para realizar a pesquisa, as mesmas palavras chave, empregadas anteriormente, ou seja: aprendizagem independente, aprendizagem autônoma e aprendizagem significativa com autonomia. Contudo, o resultado foi diferente, 
a saber, identificamos duas referências: TAVARES (2010) e BERBEL (2011). Afim de explorar-se mais estas pesquisas, foram elaboradas algumas categorias, que nos permitiu identificar as relações que existem entre as publicações, são elas: a) a melhora na motivação dos estudantes frente ao conteúdo curricular; b) indícios de aprendizagem significativa com vistas a autonomia do estudante; c) formas de investigação dos itens a e b.

\section{A melhora na motivação dos estudantes frente ao conteúdo curricular}

Segundo os resultados de Coelho, Timm e Santos (2010) a abordagem metodológica, amparada no ensino pela pesquisa, foi considerada motivadora, favorecendo atitudes como a curiosidade e o interesse dos alunos. $O$ estudo de Custódio, Pietrocola e Souza Cruz (2013) diagnosticam a "alegria" como fator responsável pelo entusiasmo frente a práxis educacional. Salientam ainda, que o entusiasmo dos discentes frente aos campos conceituais contemplados está ligado a alegria de aprender "o novo". Isso, segundo os autores, potencializará as chances dos discentes tornarem-se professores mais motivados. Na perspectiva de Araujo e Mazur (2013), alunos minimamente conhecedores dos temas a serem discutidos mostram-se mais encorajados a aprender.

A participação dos estudantes, de acordo com Bellucco e Carvalho (2014), em atividades de caráter experimental é um fator que favorece e fomenta as discussões do conteúdo estudado, no caso desta pesquisa, os conteúdos de conservação da quantidade de movimento. Isso, segundo os autores, aumentou a aprendizagem de cada estudante, na qual o conteúdo, passou a ser parte de sua vivência e não uma mera "decoreba". Massoni (2014) destaca que os estudantes se sentem motivados frente a atividades experimentais em laboratórios didáticos, mas em função da sua vivência como estudantes usam o laboratório como instrumento de verificação e não de descoberta.

Os alunos, segundo Cicuto, Mendes e Correia (2013), se mostraram instigados com o uso de uma ferramenta diferenciada de organização de conhecimento e de avaliação, ou seja, a elaboração de mapas conceituais. Além disso, é salientado no estudo que os mapas conceituais foram usados como uma ferramenta incentivadora na perspectiva de ensinar temas de Física, em situações específicas. Nas conclusões os autores sugerem o uso de tais ferramentas em outras propostas.

Campos et al. (2012) exploram a metodologia de situações problemas, apresentadas de forma experimental, com alunos da quarta série do ensino 
fundamental com o objetivo de despertar o gosto pela Ciência. Os resultados obtidos por Campos e colaboradores (2012) indicam que os estudantes conseguiram apresentar soluções frente às situações problema. Isso permitiu inferir que os alunos possuem motivação frente a temas relacionados com Ciência.

Oliveira et al. (2010) por meio de atividades periódicas, com dez encontros ao total, e usando a estratégia metodológica do ensino pela pesquisa diagnosticaram uma maior colaboração e também motivação dos estudantes frente aos temas explorados. As conclusões dos pesquisadores indicaram uma redução da evasão, muito frequente em outras propostas similares.

Toti e Pierson (2010) identificam em seu estudo, que relaciona tópicos curriculares de Física com as profissões dos estudantes, uma expressiva melhora na motivação dos discentes. Isto, segundo os pesquisadores, estabeleceu uma familiaridade da Física com o cotidiano dos estudantes, o que em última análise incentivou-os a estudar. Este resultado é também identificado por Darroz e Santos (2012) que salientam que a motivação dos estudantes aumentou com a oferta de atividades que contemplassem assuntos pertinentes a eles. O referido resultado é corroborado por Hilger e Griebeler (2013) que externam, em seu trabalho, uma melhora dos estudantes, no que se refere ao envolvimento destes na rotina escolar, quando desenvolvidos tópicos contemporâneos de Física, em particular da mecânica quântica.

A abordagem interdisciplinar é discutida por Carletto e Pinheiro (2010), num enfoque Ciência Tecnologia e Sociedade (CTS) com turmas do ensino médio. Os autores salientam que abordagens mais gerais, que neste estudo estavam direcionadas a questões ambientais, e que estabelecem conexões entre múltiplas áreas do conhecimento, potencializa a motivação e participação dos estudantes nas atividades propostas.

Fabri e Silveira (2013) relatam que os estudantes se sentiram mais motivados ao estudar tópicos de Física com enfoque em Ciência, Tecnologia e Sociedade, por meio do eixo Recursos tecnológicos, que lhes despertou a curiosidade por outros temas voltados as tecnologias e a Ciência.

A mudança de postura, frente a temas de Física, que envolvem a história da ciência, foram segundo Gatti, Nardi eSilva (2010) os pontos mais relevantes num estudo intitulado "História da ciência no ensino de física: um estudo sobre o ensino de atração gravitacional desenvolvido com futuros professores".

O incentivo a autonomia em processos de formação de docentes, foi norteada pelos pesquisadores Langhi e Nardi (2011), segundo cinco etapas: planejamento, aplicação, reflexão, socialização, envolvimento e continuidade. 
Os resultados externados pelos professores, analisados na pesquisa, indicaram o expressivo aumento na autonomia na práxis educacional.

Tavares (2010) salienta que o pluralismo metodológico, utilização de textos, animações e mapas conceituais, aumentam as chances de uma aprendizagem menos dependente do professor. Isto, segundo o autor, permite ampliar as discussões com os estudantes, levando-os a uma postura mais autônoma.

Berbel (2011) faz uma reflexão, respaldada na literatura, com enfoque na autonomia dos estudantes, por meio de metodologias ativas. A autora salienta que a participação dos estudantes frente a novos conteúdos, pela escolha, pelo interesse é a condição essencial para exercitar a liberdade e autonomia o que a longo prazo estará lhes preparando para o futuro exercício da profissão. Já, Teixeira et al. (2010) não fazem menção, na pesquisa, a respeito da motivação dos estudantes frente a metodologia implementada.

Tauceda, Nunes e Del Pino (2011) usam a metodologia do ensino pela pesquisa, por meio de atividades em laboratório e de campo, como estratégia de motivação. Isso foi feito por meio de levantamento prévio das concepções dos estudantes. Pereira, Soares e Andrade (2011) não discutem, no trabalho intitulado "Escrita como ferramenta indicativa das possíveis contribuições de uma atividade investigativa sobre temperatura para a aprendizagem" as implicações frente a motivação dos estudantes.

\section{Indícios de aprendizagem significativa com vistas a autonomia do estudante}

Coelho, Timm e Santos (2010) externam em sua abordagem, balizada por meio do ensino pela pesquisa, que os estudantes desenvolveram um senso crítico e potencializaram sua capacidade de raciocínio aproximando-se mais expressivamente do saber científico. As concepções prévias constituíram os indicativos para as abordagens posteriores.

A aprendizagem significativa, na perspectiva de Moreira (2011) é salientada por Custódio, Pietrocola e Souza Cruz(2013) por meio da diferenciação progressiva dos estudantes que explicavam os conceitos, um para o outro, e desta forma davam significado à aprendizagem. Araujo e Mazur (2013) inferem que os estudantes familiarizados com o tema apresentam maior motivação frente aos tópicos desenvolvidos, ou seja, se não tem ou tem poucos conhecimentos prévios, a leitura antecipada pode potencializar as chances de uma 
aprendizagem mais significativa do tema explorado.

Os questionamentos críticos, segundo Bellucco e Carvalho (2014), indicaram uma diferenciação em relação a outros temas abordados outrora, sendo esses fundamentais para esse processo. A pesquisadora Massoni (2014) destaca as ferramentas estatísticas como um a possibilidade de aferição da compreensão do conhecimento dos estudantes, frente à sua formação. Cicuto, Mendes e Correia (2013) usam mapas conceituais para verificar o aumento das diferenciações conceituais frente ao conteúdo explorado. Isso foi feito por meio da produção e comparação de mapas iniciais e finais. Nestes a exploração das posições e conexões entre os conceitos possibilitou o diagnóstico de compreensão mais abrangente.

Campos et al. (2012) não fizeram inserções de conteúdos específicos em sua pesquisa, desenvolvido com um grupo de estudantes da quarta série do ensino fundamental, contudo discutiram temas instigantes para esse nível de desenvolvimento cognitivo. Os resultados por eles diagnosticados indicam estudantes motivados às ciências e com alta capacidade de estruturar respostas coerentes, incompletas em alguns casos, mas com sistematização adequada.

Tauceda, Nunes e Del Pino (2011) indicam em sua pesquisa que a aprendizagem significativa ocorre se forem consideradas os conhecimentos prévios dos estudantes, bem como o seu cotidiano. Esses fatores permitem, segundo os autores, a possibilidade de reformulação dos conceitos explorados.

A articulação da escrita, como estratégia diagnóstica, objetivando rastrear indícios de uma aprendizagem significativa é usada, em sua pesquisa, por Pereira, Soares e Andrade (2011). Os pesquisadores indicaram uma reestruturação linguística, no que se refere aos conceitos explorados, que nesse caso envolviam o tema calor, indicando um aumento da compressão dos estudantes frente ao tema. Concluíram com isso que os estudantes conseguiram melhorar a compressão da temática, ou seja, construíram/reconstruíram e sistematizaram os conceitos.

O uso de práticas experimentais no ensino de Física e a educação pela pesquisa foram explorados por Oliveira et al. (2010). Nesta pesquisa, realizada ao longo dez encontros, foram consideradas as concepções prévias dos estudantes e as discussões foram feitas por meio de problematizações e confrontações que levaram à construção de um pensamento mais crítico e melhor fundamentado sobre as questões científicas. O emprego desta estratégia, segundo os autores, potencializou a aprendizagem dos participantes.

No trabalho de Darroz e Santos (2012) os indícios de aprendizagem significativa, com o foco na autonomia dos estudantes, foi diagnosticada por 
meio de mapas conceituais e reconstrução/transposição dos temas abordados para outros contextos. Os pesquisadores usam a expressão "prazer pela Ciência" para identificar a não dependência do discente para com o docente. Isto foi possível, na perspectiva dos autores, na medida em que se considerou os conhecimentos prévios dos estudantes e lhes foi solicitado a realização de tarefas que possibilitavam a diferenciação progressiva e a reconciliação integradora.

Toti e Pierson (2010) relatam, em sua pesquisa, o quão significativo foi estabelecer os conteúdos curriculares com o cotidiano dos estudantes trabalhadores. Os níveis de desenvolvimento são potencializados quando os estudantes conseguem, com o auxílio dos docentes, estabelecer relações entre os conteúdos desenvolvidos em sala de aula com temas relativos ao âmbito de seu trabalho/profissão.

Teixeira et al. (2010) usaram questionários de levantamento prévio e forneceram textos didáticos, previamente, para os estudantes matriculados na disciplina de Física I. Esta metodologia proporcionou a criação/reconstrução dos organizadores prévios dos estudantes. A utilização deste recurso didático, segundo os autores, potencializou o desenvolvimento de aprendizagem mais significativa.

Gatti, Nardi e Silva (2010) usaram os conhecimentos prévios e concepções alternativas dos estudantes, a respeito do tema Gravitação, para ampliar as discussões sobre este assunto. Como estratégia metodológica adotou-se uma perspectiva norteadora com o viés da história da Ciência. A autonomia da aprendizagem foi inferida por meio da criação de materiais didáticos, por parte dos estudantes, que usaram em suas propostas a história da ciência como "pano de fundo".

Carletto e Pinheiro (2010) salientam, na investigação, que os estudantes mostraram, por meio de discurso, excelentes indícios de compreensão dos temas explorados. O desenvolvimento desta competência discursiva indica uma aprendizagem conectada com outras áreas e, por conseguinte, com significado particular para cada estudante. A aprendizagem significativa não foi abordada de forma explicita por Langhi e Nardi (2011), em sua pesquisa, porém em seus resultados, os autores, indicam uma mudança de atitude mais comprometida e envolvida, por parte dos participantes, frente ao ensino de ciências.

A análise de Hilger e Griebeler (2013) em relação aos indícios de aprendizagem significativa foi sistematizada seguindo as orientações cunhadas por Moreira (2011) e designadas por meio da elaboração de Unidades de Ensino Potencialmente Significativas. Os indicadores de aprendizagem com significado foram relatados pelas pesquisadoras, mediante o emprego de 
análise de discurso dos estudantes envolvidos na proposta.

Segundo Fabri e Silveira (2013) as reflexões promovidas com e pelos alunos durante a após o desenvolvimento da atividade, relacionando as tecnologias com os conceitos físicos. Esta proposta, permitiu-lhes inferiu o desdobramento em relação aos conceitos explorados, permitindo segundo os autores, concluir que houve uma aprendizagem com significado, pois os temas estudados foram "internalizados" pelos estudantes.

A aprendizagem com significado, na perspectiva de Berbel (2011), está relacionada aos possíveis desdobramentos que os conhecimentos científicos podem obter ao longo da carreira do estudante, instigando-o a aumentar seu campo de conhecimentos.

Tavares (2010) apresenta os resultados de utilização de mapas conceituais e animações interativas como estratégia para fomentar a aprendizagem mais expressiva de tópicos de Física, relacionados com a Termodinâmica. Este planejamento, segundo o autor, é possível desde que sejam mapeados os conhecimentos prévios do estudante e que ele consiga interagir com os conceitos durante um longo intervalo de tempo. Somente assim, torna-se há a possibilidade de assimilar e de reconstruir os conhecimentos acerca do tema desenvolvido.

\section{Formas de investigação}

Na sequência passamos a descrever as estratégias metodológicas empregadas pelos pesquisadores em seus estudos:

Coelho, Timm e Santos (2010) usaram a observação direta e a análise discurso, mesmo sem referenciação teórica, como ferramenta de avaliação dos resultados. Custódio, Pietrocola e Souza Cruz (2013) fazem uso da análise de discurso, por meio da repetição de expressões. Araujo e Mazur (2013) incentivam o uso de análise estatística de respostas para encaminhar as atividades posteriores.

A análise das respostas, para problemas abertos, de acordo com Bellucco e Carvalho (2014), sobre o conceito de conservação da quantidade de movimento, possibilitaram a análise do aumento do campo conceitual estruturado dos estudantes no que se refere ao tema desenvolvido. Massoni (2014) usa a análise estatística como ferramenta investigativa dos dados.

A comparação de mapas conceituais, segundo Cicuto, Mendes e Correia (2013), permitiu, por meio da análise da posição e hierarquização 
dos conceitos, diagnosticar o grau de compreensão dos estudantes frente ao tema. Para quantificar os resultados, os autores fizeram estatísticas do uso de palavras e expressões que mais se fizeram presentes nos mapas conceituais.

Campos et al. (2012) usam a pictografia dos estudantes, alunos da quarta série do ensino fundamental, para ilustrar a solução frente as situações problemas. A análise dos resultados considerou além dos desenhos, a fala e a escrita dos estudantes.

A análise de respostas, frente a situações problemas/questões instigadoras, foi usada por Tauceda, Nunes e Del Pino (2011) para diagnosticar, primeiramente, as concepções prévias dos estudantes e, em segunda instância, para explorar/desenvolver os temas escolhidos. Pereira, Soares e Andrade (2011) usam a análise da escrita como ferramenta indicativa das possíveis contribuições de uma atividade investigativa sobre temperatura.

O relato dos estudantes, da professora e da bolsista foram os instrumentos usados por Oliveira e colaboradores (2010) para sistematizar os resultados da pesquisa. Este método possibilitou o diagnóstico dos conhecimentos prévios, o uso de atividades experimentais e o ensino pela pesquisa, que por sua vez, potencializou as chances de uma aprendizagem mais significativa.

Darroz e Santos (2012) usam no estudo, relacionado com conceitos de Astronomia, mapas conceituais para aferir a compreensão dos estudantes acerca da temática. Além disto, a verificação dos indícios de aprendizagem significativa foi diagnosticada por meio de tarefas de transposição dos assuntos abordados para outros contextos.

Toti e Pierson (2010) usaram a análise discursiva como ferramenta de investigação. Ademais, organizaram, em conjunto com os estudantes que já tinham uma profissão, tabelas estabelecendo quais tópicos de Física poderiam ser desenvolvidos em cada profissão. A qualidade na argumentação escrita, acerca de tópicos de Física Clássica, em particular sobre a teoria newtoniana, é usada por Teixeira et al. (2010) em sua pesquisa. Para isso as aulas foram gravadas e posteriormente transcritas.

O estudo de caso, com abordagem qualitativa é também usada por Gatti, Nardi eSilva (2010) num estudo envolvendo docentes em cursos de formação continuada, com enfoque em temas de Física relacionados com a História da Ciência.

Carletto e Pinheiro (2010) utilizaram como metodologia a pesquisa qualitativa, de natureza interpretativa, em que os autores apresentaram percentuais de melhora e/ou modificação dos conceitos compreendidos pelos estudantes. 
Langhi e Nardi (2011) objetivam em sua pesquisa responder a seguinte questão: quais os indícios de construção da autonomia docente podem ser atingidos durante processos formativos reflexivos, contemplados semestralmente nas disciplinas de Metodologia e Prática de Ensino de Física, de um curso de Licenciatura em Física? Para aferir os resultados da pesquisa foi usado, pelos estudiosos, os procedimentos metodológicos: grupo focal, coaching, auto confrontação e avaliação formativa, tendo a análise de discurso como pano de fundo.

A metodologia desenvolvida pelas pesquisadoras Hilger e Griebeler (2013) foi amparada pelas Unidades de Ensino Potencialmente Significativas, com o foco em Mecânica Quântica, e tiveram como foco de estudo a análise do discurso dos estudantes e também a utilização de mapas conceituais organizados e apresentados pelos estudantes. Nesta mesma perspectiva, Fabri e Silveira (2013) usaram a análise de discurso escrito, entrevista e questões para aferir e validar suas conclusões.

A proposta, respaldada numa pesquisa na literatura, de Berbel (2011), está ligada a possibilidade de investigar situações que fomentem a aprendizagem autônoma. Entre elas, destaca-se o estudo de casos com resoluções de problemas específicos, problematizações, ensino pela pesquisa, atividades experimentais, relação teoria e prática. Estas e outras metodologias, segunda a autora, que as denomina como metodologias ativas, requerem do professor um amplo conhecimento do tema e um engajamento permanente.

Tavares (2010) usou a construção de mapas conceituais, por parte dos estudantes, para diagnosticar indícios de compreensão do tema, que foram feitos após o desenvolvimento das temáticas por meio de textos, animações interativas sobre a temática termodinâmica.

\section{Nova cultura educacional no ensino e aprendizagem da ciência}

Diferentemente de uma abordagem tradicional, notadamente positivista, a epistemologia com enfoque construtivista entende que aprender e ensinar, não são meros processos de repetição e acumulação de conhecimentos, implicam transformar a mente de quem aprende, que deve reconstruir em nível pessoal os produtos e processos culturais com o fim de se apropriar deles(CARRETERO, 1997). Essa ideia não é nova, porém devido às mudanças ocorridas na forma de produzir, organizar e distribuir os conhecimentos científicos em nossa sociedade torna-se necessário estender essa forma de aprender 
e ensinar para todos os âmbitos formativos e para o ensino das ciências.

Concebeu-se, durante muito tempo, a ideia de o conhecimento científico surge da observação adequada da natureza. Tudo o que era preciso fazer para descobrir uma lei científica era observar e coletar dados da maneira adequada, pois deles surge a verdade. Essa imagem da ciência como um processo de descobrimento de leis ainda continua vigente nas salas aula. Continua-se ensinando que o conhecimento científico é baseado na aplicação rigorosa do método científico, que deve começar pela observação dos fatos, do qual devem ser extraídas as leis e os princípios (ISKANDAR; LEAL, 2002).

Essa concepção positivista, segundo a qual a ciência é uma coleção de fatos objetivos governados por leis que podem ser extraídas via observação da realidade com uma metodologia adequada, foi superada, mas não necessariamente nas salas de aula, por novas concepções epistemológicas, segundo as quais o conhecimento científico nunca se extrai da realidade, mas surge e ganha vida a partir da mente dos cientistas, que elaboram modelos e teorias na tentativa de dar sentido a essa realidade. Superada a chamada onda positivista, hoje parece ser um fato assumido que a ciência não é um discurso sobre o real, mas um processo socialmente definido de elaboração de modelos para interpretar a realidade.

Segundos os pressupostos epistemológicos do construtivismo, as teorias científicas não são saberes absolutos ou positivos, mas aproximações relativas, construções sociais que, longe de descobrir a estrutura do mundo ou da natureza, constroem ou modelam essa estrutura. As teorias científicas resultam da interação entre a teoria e a parte da realidade interrogada por meio de certos métodos ou instrumentos. Os conceitos e as leis que compõem as teorias científicas não estão na realidade, mas são parte dessas mesmas teorias (CARRETERO, 1997).

Hodiernamente, boa parte da ciência de ponta, de fronteira, é baseada, cada vez mais, no paradigma da simulação, mais do que no experimento em si, o que supõe uma importante revolução na forma de fazer ciência e de concebê-la. As ciências cognitivas, não descobrem como são as coisas indagando a realidade, mas constroem modelos e, a partir deles, simulam certos fenômenos, comprovando seu grau de ajuste ao que conhecemos da realidade. Aprender ciência deve ser, portanto, um exercício de comparar e diferenciar modelos, não de adquirir saberes absolutos. A chamada mudança conceitual, necessária para que o aluno progrida dos seus conhecimentos intuitivos aos científicos, requer pensar nos e não só com os diversos modelos e teorias a partir dos quais é possível interpretar a realidade. 
Portanto, para Popper (1963) a ciência é um processo e não apenas um produto acumulado em forma de teorias ou modelos, e é necessário levar para os alunos esse caráter dinâmico e perecedouro dos saberes científicos, fazendo com que percebam sua transitoriedade e sua natureza histórica e cultural, que compreendam as relações entre o desenvolvimento da ciência, a produção tecnológica e a organização social, entendendo, o compromisso da ciência com a sociedade, em vez da neutralidade e objetividade do suposto saber positivo da ciência. Ensinar ciências não deve ter como meta apresentar aos alunos os produtos da ciência como saberes acabados e definitivos. Pelo contrário, a ciência deve ser ensinada como um saber histórico e provisório, tentando fazer com que os alunos participem no processo de elaboração do conhecimento científico, com suas dúvidas e incertezas, e isso também requer deles uma forma de abordar o aprendizado como um processo construtivo, de busca de significados e de interpretação, em vez de reduzir a aprendizagem a um processo repetitivo ou de reprodução de conhecimentos prontos para o consumo (ELLWANGER; ALVES; FAGAN, 2016).

Esses pressupostos epistemológicos e a concepção da ciência como processo de construção de modelos e teorias exigem adotar um enfoque construtivista no ensino das ciências. Nessa perspectiva, não é mais possível conceber a aprendizagem como uma atividade apenas de reprodução ou cumulativa. Contudo, a aprendizagem escolar tende a exigir dos alunos aquilo para o que eles estão menos dotados: repetir ou reproduzir as coisas com exatidão.

Nesse sentido, faz-se necessário uma mudança cultural na forma de aprender e ensinar. Um sistema educacional, mediante o estabelecimento dos conteúdos das diferentes disciplinas que compõem o currículo, tem como função formativa fazer com que os futuros cidadãos interiorizem e assimilem a cultura em que vivem, compartilhem as produções artísticas, científicas e técnicas, próprias dessa cultura e compreendam o seu sentido histórico, mas, também, desenvolvam as capacidades necessárias para acessar esses produtos culturais, desfrutar deles e renová-los. Mas essa formação cultural ocorre no marco de uma cultura da aprendizagem, que evolui com a própria dinâmica da sociedade.

Cada revolução cultural repercute na organização e distribuição social do saber e traz consigo uma revolução paralela na cultura da aprendizagem, a mais recente das quais ainda não terminou: as novas tecnologias da informação, unidas a outras mudanças sociais e culturais, estão abrindo espaço para uma nova cultura da aprendizagem, que transcende o marco da cultura impressa e deve condicionar os fins sociais da educação. Pode-se caracterizar esta nova 
cultura de aprendizagem a partir de três traços essenciais.

Na sociedade da informação a escola não é mais a primeira fonte de conhecimento para os alunos em muitos domínios. Inclusive, na atualmente, são poucas as informações reservadas à escola (COSTA SANTOS; CARVALHO, 2009). Os alunos são bombardeados por diversas fontes que chegam, inclusive, a produzir uma saturação informativa. Essas informações possuem formatos quase sempre mais ágeis e atraentes do que os utilizados na escola. Nesse contexto, entende-se que os alunos da educação científica precisam não tanto de mais informação, mas, sobretudo, de capacidade para organizá-la e interpretá-la, para lhe dar sentido. A escola não pode mais proporcionar toda a informação relevante, porque esta é muito mais móvel e flexível do que a própria escola. Entretanto, o que a escola pode fazer é formar os alunos para que possam acessar essas informações e dar-lhes sentido, proporcionando capacidades de aprendizagem que permitam uma assimilação crítica de toda a informação.

Como consequência dessa multiplicação informativa, mas também de mudanças culturais mais profundas, vive-se também em uma sociedade de conhecimento múltiplo e descentralizado(CRUZ, 2008). A evolução do conhecimento científico segue um processo de descentralização progressiva dos saberes. Não restam saberes ou pontos de vista absolutos que, como futuros cidadãos, os alunos devam assumir; o que devem é aprender a conviver com a diversidade de perspectivas, com a relatividade das teorias, com a existência de interpretações múltiplas de toda informação. E devem aprender a construir seu próprio julgamento ou ponto de vista a partir de tudo isso, pois a ciência do século $X X$ se caracteriza pela perda da certeza.

Em contrapartida, vive-se na sociedade do aprendizado contínuo em que boa parte dos conhecimentos que podem ser proporcionados hoje aos alunos não só são relativos, mas têm data de vencimento (PALLARES-BURKE, 2004). Neste ritmo de mudanças tecnológicas e científicas, ninguém pode prever o que precisarão saber os cidadãos no futuro para poder enfrentar as demandas sociais. O que podemos garantir é que terão de continuar aprendendo. O processo de formação profissional cada vez se prolonga mais e devido à mobilidade e ao aparecimento de novos e imprevisíveis perfis laborais, torna-se cada vez mais necessária uma formação permanente. O sistema educacional não pode proporcionar formação específica para cada uma dessas necessidades. Contudo, trata-se de formar os futuros cidadãos para que eles sejam aprendizes mais flexíveis, eficientes e autônomos, dotando-os de capacidades de aprendizagem (ZYGMUNT, 2001). Assim, "aprender a aprender" constitui 
uma das demandas essenciais que o sistema educacional deve dar conta. O currículo de ciências é uma das vias por meio das quais os alunos devem aprender a aprender, adquirir estratégias e capacidades para transformar, reelaborar e reconstruir os conhecimentos.

Enfim, a eficácia da educação científica deverá ser medida pelo que se consegue que os alunos realmente aprendam. E para isso é necessário que as metas, os conteúdos e os métodos de ensino da ciência levem em consideração não apenas o saber disciplinar que deve ser ensinado, mas também as características dos alunos a quem esse ensino é dirigido e as demandas sociais e educacionais que esse ensino deve satisfazer.

\section{Então quais são as condições necessárias para instigar a autonomia?}

Aprender com significado, segundo Ausubel (2000), é ampliar e reconfigurar as ideias já existentes na estrutura cognitiva da pessoa, e com isso estabelecer novas conexões, com novos temas. Nessa perspectiva, os relatos analisados salientam que para criar condições favoráveis a uma aprendizagem significativa é crucial o levantamento dos conhecimentos prévios dos estudantes. Alguns pesquisadores usam a expressão subsunçores como sinônimo de conhecimento prévio. Além disso, estabelecer relações dos conteúdos curriculares com o cotidiano do estudante, seja esse a profissão ou o seu entorno, maximiza o empenho dos estudantes nas atividades propostas e também os incentiva a extrapolar os tópicos desenvolvidos nas aulas.

Os materiais didáticos, para ser potencialmente significativos, devem ser organizados, segundo os estudos investigados, de tal forma que possam ser discutidos, ampliados e modificados no desenvolvimento das propostas. Essa preocupação aliada ao pluralismo metodológico (construção de mapas conceituais, situações problema, estudo pela pesquisa, visitas dirigidas, uso de tecnologias e outras), permitem inferir que nenhuma metodologia sozinha é eficaz. O uso de múltiplas metodologias, de acordo com o tema desenvolvido, mostra-se uma estratégia eficiente.

O incentivo a autonomia dos estudantes é fomentado na organização/ reorganização de materiais que poderão ser usados em outros contextos. Esse tipo de atividade, ou seja, a produção autônoma, visou, segundo o relato dos pesquisadores, uma desvinculação da relação: professor ensina $\rightarrow$ aluno aprende e configurou uma cena professor $\leftrightarrow$ aluno.

Além disso, a utilização de ferramentas diferenciadas de avaliação 
e diagnóstico, como por exemplo mapas conceituais, textos dissertativos, esquemas, relatórios e discursos orais encorajou os estudantes a externar seus conhecimentos sem temor. A discrepância de entendimentos foi explorada num viés reconstrutivo, o que em última análise tornou-se uma ferramenta de ensino.

Por fim, a aprendizagem significativa com a perspectiva da autonomia, foi identificada nos relatos como sendo um estado de felicidade no ato de aprender.

Por fim, o ensino de Ciência, e seus problemas, é discutido por especialistas a muito tempo. Pouco dos resultados das pesquisas tem sido levado, de fato e de forma efetiva, para a sala de aula.

Resultados encorajadores, apresentados neste trabalho, permitem inferir que há alternativas para o panorama atual - alunos desmotivados, passividade dos discentes, currículos engessados.

Considerar o que o aluno já sabe, preocupar-se em organizar um material útil para a vida do estudante e avalia-lo por meio de ferramentas honestas podem atenuar a apatia discente e tornar o estudante mais engajado e mais independente. Estas são algumas das conclusões deste levantamento.

\section{Referências}

ELLWANGER, A. L. ; ALVES, M. A.; FAGAN, S. B. As implicações da Epistemologia de Popper no Ensino de Ciências. Vidya (Santa Maria. Online), v. 36, p. 15-27, 2016.

ARAUJO, I.; MAZUR, E. Instrução pelos colegas e ensino sob medida: uma proposta para o engajamento dos alunos no processo de ensino-aprendizagem de Física. Caderno Brasileiro de ensino de Ciências, v. 30, n. 2: p. 362-384, ago. 2013. Disponível em: <https://periodicos.ufsc.br/index.php/fisica/article/ view/2175-7941.2013v30n2p362>Acesso em: 16 jun. 2015.

AUSUBEL, D. The acquisition and retention of knowledge: A cognitive view. Dordrecht: Kluwer Academic Publishers, 2000.

BELLUCCO, A.; CARVALHO, A.Uma proposta de sequência de ensino investigativa sobre quantidade de movimento, sua conservação e as leis de Newton. Caderno Brasileiro de ensino de Ciências. v. 31, n. 1, p. 30-59, abr. 2014. Disponível em:

<https://periodicos.ufsc.br/index.php/fisica/article/view/2175-7941.2014v31n1p30>. Acesso em: 16 jun. 2015. 
BERBEL, N. A. N. As metodologias ativas e a promoção da autonomia de estudantes. Semina: Ciências Sociais e Humanas. v. 32, n.1, p. 25-40 (2011). Disponível em:

<http://www.uel.br/revistas/uel/index.php/seminasoc/article/ view/10326/10999> Acesso em: 16 jun. 2015.

CAMPOS, B.S.; FERNANDES, S.A.; RAGNI, A.C.P.B.; SOUZA, N.F.Física para crianças: abordando conceitos físicos a partir de situações-problema.Revista Brasileira de ensino de Física, v. 34, n. 1, 1402, 2012.

Disponível em: http://www.sbfisica.org.br/rbef/pdf/341402.pdf.Acesso em: 17 jun. 2015.

CARLETTO, M.; PINHEIRO, N. Subsídios para uma prática pedagógica transformadora: contribuições do enfoque CTS.Investigações em Ensino de Ciências, v. 15, n. 3, p. 507- 525, 2010.Disponível em: http://www.if.ufrgs.br/ienci/artigos/Artigo_ID247/v15_n3_a2010.pdf. Acesso em: 13 jun. 2015.

CARRETERO, M. Construtivismo e educação. Porto Alegre: Artes Médicas, 1997.

CICUTO, C.; MENDES, B.; CORREIA, P.Nova abordagem para verificar como os alunos articulam diferentes materiais instrucionais utilizando mapas conceituais.Revista Brasileira de ensino de Física, v. 35, n. 3, 3402, 2013.Disponível em:http://www.sbfisica.org.br/rbef/pdf/353402.pdf. Acesso em: 17 jun. 2015.

COELHO, S.; TIMM, R.; SANTOS, J.Educar pela pesquisa: uma experiência investigativa no ensino e aprendizagem de Física.Caderno Brasileiro de ensino de Ciências,v. 27, n. 3: p. 549-567, dez. 2010. Disponível em:

<https://periodicos.ufsc.br/index.php/fisica/article/view/2175-7941.2010v27n3p549> Acesso em: 17 jun. 2015.

CRUZ, J. M. O.. Processo de ensino-aprendizagem na sociedade da informação. Educação \& Sociedade (Impresso), v. 29, p. 1023-1042, 2008. 2010. Disponível em: http://www.scielo.br/pdf/es/v29n105/v29n105a05Acesso em: 25 jun. 2015.

CUSTÓDIO, J. F.; PIETROCOLA, M.; SOUZA CRUZ, F. F.Experiências emocionais de estudantes de graduação como motivação para se tornarem professores de Física.Caderno Brasileiro de ensino de Ciências, v. 30, n. 1: p. 25-57, abr. 2013. 
Disponível em: https://periodicos.ufsc.br/index.php/fisica/article/view/ 2175-7941.2013v30n1p25. Acesso em: 17 jun. 2015.

DARROZ, L.; SANTOS, F.Promovendo a aprendizagem significativa de conceitos básicos de astronomia na formação de professores em nível médio.Experiências em ensino de Ciências, v. 07, n. 2, 2012.Disponível em:http://if.ufmt. br/eenci/artigos/Artigo_ID178/v7_n2_a2012.pdf Acesso em: 17 jun. 2015.

FABRI, F.; SILVEIRA, R. O ensino de ciências nos anos iniciais do ensino fundamental sob a ótica CTS: uma proposta de trabalho diante dos artefatos tecnológicos que norteiam o cotidiano dos alunos.Investigações em Ensino de Ciências, v. 18, n. 1, p. 77- 105, 2013.

Disponível em: http://www.if.ufrgs.br/ienci/artigos/Artigo_ID321/v18_n1_ a2013.pdf. Acesso em: 10 jun. 2015.

GATTI, S.; NARDI, R.;SILVA, D. História da ciência no ensino de física: um estudo sobre o ensino de atração gravitacional desenvolvido com futuros professores.Investigações em Ensino de Ciências, v. 15, n. 1, p. 7- 59, 2010.

Disponível em: http://www.if.ufrgs.br/ienci/artigos/Artigo_ID227/v15_n1_ a2010.pdf. Acesso em: 13 jun. 2015.

HILGER, T.; GRIEBELER, A. Uma proposta de unidade de ensino potencialmente significativo utilizando mapas conceituais. Investigações em Ensino de Ciências, v. 18, n. 1, p. 199- 213, 2013. Disponível em: http://www.if.ufrgs.br/ ienci/artigos/Artigo_ID327/v18_n1_a2013.pdf. Acesso em: 01 jun. 2015.

ISKANDAR, J. I.; LEAL, M. R. Sobre positivismo e educação. Revista Diálogo Educacional, Curitiba, v. 3, n.7, p. 89-94, set./dez. 2002. Disponível em:

https://periodicos.pucpr.br/index.php/dialogoeducacional/article/ view/4897/4855 Acesso em: 01 agos. 2015.

LANGHI, R.; NARDI, Roberto. Interpretando reflexões de futuros professores de física sobre sua prática profissional durante a formação inicial: a busca pela construção da autonomia docente.Investigações em Ensino de Ciências, v. 16, n. 3, p. 403- 424, 2011.

Disponível em: http://www.if.ufrgs.br/ienci/artigos/Artigo_ID269/v16_n3_ a2011.pdf . Acesso em: 12 jul. 2015.

MASSONI, N. Ensino de laboratório em uma disciplina de Física Básica voltada para cursos de Engenharias: análises e perspectivas. Caderno Brasileiro de ensino de Ciências, v. 31, n. 2, p. 258-288, ago. 2014. Disponível em: https://pe- 
riodicos.ufsc.br/index.php/fisica/article/view/2175-7941.2014v31n2p258. Acesso em: 16 jul. 2015.

MOREIRA, M. A. Unidades de Enseñanza Potencialmente Significativas UEPS. Aprendizagem Significativa em Revista / Meaningful Learning Review, v.1, n.2, p. 43-63. 2011. Disponível em: http://www.if.ufrgs.br/asr/?go=artigos\&idEdicao=2. Acesso em: 15 jul. 2015.

MOTA, R.; SCOTT, D. Educando para a Inovação e a Aprendizagem Independente. Rio de Janeiro. Elsevier, 178p. 2014.

OLIVEIRA, M.; COSTA, R.; SOTELO, D.; ROCHA FILHO, J.Práticas experimentais de física no contexto do ensino pela pesquisa: uma reflexão. Experiências em ensino de Ciências, v.5, n. 3, 2010.Disponível em: http://if.ufmt.br/eenci/artigos/Artigo_ID119/v5_n3_a2010.pdf. Acesso em: 17 agos. 2015.

PALLARES-BURKE, M. L. G. Entrevista com Zigmunt Bauman. Tempo soc., São Paulo, v. 16, n. 1, p. 301-325, Junho 2004. Disponível em: <http://www.scielo.br/scielo.php?script=sci_arttext\&pi$\mathrm{d}=\mathrm{S} 0103-20702004000100015 \& \mathrm{nng}=\mathrm{en} \& \mathrm{nrm}=\mathrm{iso}>$. Acessado em 05 maio de 2017.

PEREIRA, M.; SOARES, V.; ANDRADE, V.Escrita como ferramenta indicativa das possíveis contribuições de uma atividade investigativa sobre temperatura para a aprendizagem. Experiências em ensino de Ciências, v.6, n. 3, 2011.

Disponível em:<http://if.ufmt.br/eenci/artigos/Artigo_ID164/v6_n3_a2011. pdf>. Acesso em: 17 agos. 2015.

POPPER, K. R. Conjecturas e Refutações. Coimbra: Almedina, 1963. SANTOS, P. L. V. A. C.; GROSSI, A. Sociedade da informação: avanços e retrocessos no acesso e no uso da informação. Informação \& Sociedade (UFPB. Impresso), v. 19, p. 45-55, 2009. Disponível em: http://www.periodicos.ufpb. br/ojs2/index.php/ies/article/view/1782/2687Acesso em: 17 agos. 2015

TAUCEDA, K.; NUNES, V.; DEL PINO, J. C.A epistemologia/ metodologia do aluno pesquisador na educação em ciências. Experiências em ensino de Ciências, v.6, n. 3, 2011.

Disponível em:http://if.ufmt.br/eenci/artigos/Artigo_ID165/v6_n3_a2011. pdf. Acesso em: 17 jun. 2015.

TAVARES, R. Aprendizagem significativa, codificação dual e objetos de aprendizagem. Revista Brasileira de Informática na Educação, v.18, n.2, 2010. Disponível em: http://www.fisica.ufpb.br/ ROMERO/pdf/2010RBIERomero.pdf. 
Acesso em: 18 jun. 2015.

TEIXEIRA, E.; SILVA NETO, C.;FREIRE Jr, O.; GRECA, I. A construção de uma argumentação sobre a síntese newtoniana a partir de atividades em grupos. Investigações em Ensino de Ciências, v. 15, n. 1, p. 61- 95, 2010. Disponível em: http://www.if.ufrgs.br/ienci/artigos/Artigo_ID229/v15_n1_a2010.pdf.. Acesso em: 14 jun. 2015.

TOTI, F.; PIERSON, A. Elementos para uma aproximação entre a física no ensino médio e o cotidiano de trabalho de estudantes trabalhadores.Investigações em Ensino de Ciências, v. 15, n. 3, p. 527- 552, 2010.Disponível em: http://www.if.ufrgs.br/ienci/artigos/Artigo_ID248/v15_n3_a2010.pdf. Acesso em: 13 jun. 2015.

ZYGMUNT B.Modernidade líquida.Jorge Zahar Editor: Rio de Janeiro, 2001.

Data de recebimento: 25.05 .2017

Data de aceite: 15.03 .2018 